\title{
Effect of the Refining Process on Total Hydroxytyrosol, Tyrosol, and Tocopherol Contents of Olive Oil
}

\author{
Paolo Lucci ${ }^{1, *}$, Valentina Bertoz ${ }^{1}$, Deborah Pacetti ${ }^{2}$, Sabrina Moret ${ }^{1}$ and Lanfranco Conte ${ }^{1}$ \\ 1 Department of Agri-Food, Animal and Environmental Sciences, University of Udine, via Sondrio 2/a, \\ 33100 Udine, Italy; bertoz.valentina@spes.uniud.it (V.B.); sabrina.moret@uniud.it (S.M.); \\ lanfranco.conte@uniud.it (L.C.) \\ 2 Department of Agricultural, Food, and Environmental Sciences, Marche Polytechnic University, Via Brecce \\ Bianche, 60131 Ancona, Italy; d.pacetti@staff.univpm.it \\ * Correspondence: paolo.lucci@uniud.it; Tel.: +39-0432-55817
}

Received: 16 January 2020; Accepted: 2 March 2020; Published: 5 March 2020

check for updates

\begin{abstract}
The impact of the olive oil refining process on major antioxidant compound levels was evaluated by means of UHPLC analysis of lampante olive oils collected at different stages of the refining procedure (degumming, chemical and physical flash neutralization, bleaching, and deodorization). For this purpose, the evolution of the tocopherol fraction was investigated by means of the UHPLC-FL method, while the influence of the refining process on the total hydrolyzed phenolic content was assessed by measuring hydroxytyrosol and tyrosol levels after acid hydrolysis of the phenolic extracts. Refining was found to have a marked effect on total hydroxytyrosol and tyrosol contents, as they are completely removed in the early steps of the refining procedure. In contrast, the variation trends of tocopherols are not always clear-cut, and significant decreases in content from $7 \%$ to $16 \%$ were only revealed during refining in four out of nine samples. In addition, five of the nine refined oils showed final tocopherol concentrations higher than $200 \mathrm{mg} / \mathrm{kg}$, the limit imposed by international standards regarding the content of such compounds in commercial olive oils. This study supports the need for a revision of the International Olive Oil Council (IOC) standard relative to the limit established for tocopherol addition to refined oils to avoid possible legal and economic trade issues.
\end{abstract}

Keywords: hydroxytyrosol; lampante oil; olive oil; phenolic compounds; refining; tyrosol; tocopherols; ultra-high performance liquid chromatography

\section{Introduction}

Extra virgin and virgin olive oils are obtained solely through physical means by mechanical or direct pressing of the olives. They are not subjected to any treatment other than washing, decantation, centrifugation, and filtration, and they may be consumed without refining. In contrast, "lampante" olive oils, which represent another category of mechanically extracted olive oils, are unfit for direct human consumption and have to be refined prior to use. According to the International Olive Oil Council (IOOC), refined olive oil is the olive oil obtained from lampante olive oils by refining methods that do not lead to alterations in the initial glyceridic structure. It has a free acidity, expressed as oleic acid, of no more than $0.3 \mathrm{~g}$ oleic acid/100 $\mathrm{g}$ oil, and its other characteristics correspond to those fixed for this category in the IOOC standards [1].

Most of the world's olive oil is produced in countries in the Mediterranean Basin. However, a significant amount of oil produced in the Mediterranean area (over 20\% of total production) is of such poor quality that it must be refined in order to be fit for human consumption [2]. One main purpose of a refining plant is to produce edible oils with low acidity values [3]. Moreover, other minor substances that can affect the quality of the oil, such as phospholipids, pigments, peroxides, 
traces of metals, herbicides, and volatiles responsible for sensory defects, are also removed or their content reduced during refining treatments [4,5]. It should be stressed, however, that although refining aims to extend the shelf-life of oils by removing undesirable compounds, it also results in the loss of molecules of biological and technological interest such as tocopherols and phenolic compounds [6]. Polyphenols present in olive oil act as antioxidants mainly in the initial phase of autoxidation by scavenging free radicals and as chelating agents against metals $[7,8]$. The phenolic compounds present in olive oil include tyrosol, hydroxytyrosol, hydroxybenzoic acid, oleuropein, caffeic acid, vanillic acid, $p$-coumaric acid, and tyrosol and hydroxytyrosol derivatives [9]. On the other hand, tocopherols, which are recognized as important lipid oxidation inhibitors in food and biological systems, represent the most abundant lipophilic antioxidants in olive oils, with levels usually ranging from 5 to $400 \mathrm{mg} / \mathrm{kg}$, with $\alpha$-tocopherol being the main isomer $[5,10,11]$.

The quantity of antioxidants that are lost during the refining process depends on the severity and the conditions employed. In the neutralization step, phenolic substances are destroyed or reduced. Tocopherols can also be partially removed during the deodorization/distillation steps in both chemical and physical refining processes [12]. For instance, in physical neutralization, tocopherols may be distilled and removed from sample together with small amounts of sterols, about $100 \%$ of squalene, etc. $[6,13]$. The decrease in antioxidant levels as a result of the refining process is relevant because oxidative stability is not only a quality parameter but also represents one of the most important oil indicators of shelf-life [14]. During oxidation, compounds responsible for unpleasant odors are produced, thus making the oil less acceptable or unacceptable for the consumer or for the industries that use it as an ingredient. In edible oils, oxidation is influenced by energy sources such as light or heat, concentration and type of oxygen, oil treatment, minor components such as transition metals and pigments, and antioxidant content, among others [15]. For this reason, the supplementation of tocopherols is allowed both by the Codex Alimentarius and by the IOC for refined oils only, with the aim of restoring natural tocopherols lost in the refining process $[1,16]$. However, the concentration of $\alpha$-tocopherol in the final product must not exceed $200 \mathrm{mg} / \mathrm{kg}$, thus representing a problem in international trade in some cases because "high-quality" olive oils (mixtures of refined and extra virgin olive oils) can frequently and naturally exceed the set limit. Therefore, this study aimed (1) to examine the effect the different refining steps would have on the tocopherol content of lampante oil samples; and (2) to determine whether the magnitude of their content decrease would have practical implications regarding the maximum level established for $\alpha$-tocopherol by the international standards for olive oils. Additionally, considering the impact of polyphenols on oil stability as well as the health claims recently approved by the European Food Safety Authority for olive oil polyphenols (Commission Regulation (EU) 432/2012) [17], (3) the influence of the refining processes on the total content of hydroxytyrosol and tyrosol after acid hydrolysis was also investigated by applying a UHPLC-UV method.

\section{Materials and Methods}

\subsection{Chemicals}

Acetone, acetonitrile, isopropanol, ethanol, methanol, and $n$-hexane, (all HPLC grade) were purchased from Sigma-Aldrich (Milano, Italia). Water was purified with a Milli-Q system (Millipore, Bedford, MA, USA). All other reagents were of analytical grade. $5 \alpha$-cholestanol, tocopherol $(\alpha, \gamma$ and $\delta$-tocopherols), and phenolic acid (tyrosol and hydroxytyrosol) standards were purchased from Sigma-Aldrich (Milano, Italia).

\subsection{Industrial Samples}

Lampante olive oil samples $(n=9)$ were industrially refined using the common refining process under the following conditions: degumming with deionized water for $30 \mathrm{~s}$ at $80{ }^{\circ} \mathrm{C}$; chemical neutralization up to about $0.2 \%$ of free acidity with sodium hydroxide $(23.5 \%)$; physical flash neutralization at $230{ }^{\circ} \mathrm{C}$ at $1 \mathrm{mbar}$ to reach about $0.02 \%$ free acidity; bleaching with $3 \%$ bleaching earth 
mix containing $5 \%$ activated carbon at $90-97^{\circ} \mathrm{C}$ at $20 \mathrm{mbar}$; and deodorization at $200{ }^{\circ} \mathrm{C}$ at $2 \mathrm{mbar}$ for about $2.5 \mathrm{~h}$. Oil samples $(3 \mathrm{~L})$ were therefore taken at different stages of the refining procedure (crude oil, degummed oil, neutralized oil, bleached oil, deodorized oil) and kept frozen in dark glass bottles at $-18{ }^{\circ} \mathrm{C}$ until chemical analyses were performed.

\subsection{Commercial Samples}

Eleven commercial refined olive oils were purchased at local markets.

\subsection{Analytical Determinations for Quality and Purity Assessment}

Determination of acidity as oleic acid and specific UV absorption at $232 \mathrm{~nm}$ (K232) and 270 $\mathrm{nm}$ (K270), as well as quantification of fatty acid methyl esters, sterols, dialcohols, and waxes, were performed according to the procedure reported in Regulation EC/2568/91 [18]. The difference between theoretical and experimental equivalent carbon number $42(\triangle \mathrm{ECN} 42)$ was determined according to the IOC method for ECN42 analysis [19].

\subsection{UHPLC Analysis of Tocopherols}

For the determination of tocopherols in oil samples, a new UHPLC method was developed and validated in-house. Analysis were realized using a Shimadzu Nexera (Shimadzu, Kyoto, Japan) UHPLC coupled with same components used for polyphenols analysis and the fluorescence detector RF-20Axs with double acquisition channels and a 12- $\mu \mathrm{L}$ cell. The detector wavelengths were set at 296 $\mathrm{nm}$ (excitation energy) and $325 \mathrm{~nm}$ (emission energy). Acquisition frequency was $10 \mathrm{~Hz}$. The sample was diluted in 2-propanol at a $100 \mathrm{mg} / \mathrm{mL}$ concentration and $1 \mu \mathrm{L}$ injected on column as compromise between the required sensitivity and the capacity of the column. The chromatographic separation was performed using an Agilent Eclipse PAH column $(1.8 \mu \mathrm{m}$ particle size, $4.6 \mathrm{~mm} \times 50 \mathrm{~mm})$ under isocratic elution using as a mobile phase a mixture of methanol/acetonitrile $(60 / 40, v / v)$ with a flow rate of $600 \mu \mathrm{L}$ $\mathrm{min}^{-1}$. Oven temperature was set at $30^{\circ} \mathrm{C}$. The injected volume for each sample was $1 \mu \mathrm{L}$. Tocopherols were quantified using three different calibration curves for $\alpha, \gamma$, and $\delta$ in the range $0.05-100$ ng injected on column. The performance of the UHPLC method was deeply investigated (linearity, repeatability, matrix effect) in order to check its suitability for tocopherol detection in oil samples.

\subsection{UHPLC Analysis of Phenolic Compounds}

Extraction of phenolic compounds was performed according to the official IOC method [20]. Then, acid hydrolysis was applied following the procedure suggested by Rovellini et al. [21]. Briefly, $1 \mathrm{~mL}$ of methanolic extract was dried on a warm bath at $40{ }^{\circ} \mathrm{C}$ under a gentle steam of nitrogen and then hydrolyzed with $1 \mathrm{~mL}$ of ethanol/water/sulfuric acid $(50 / 40 / 20, v / v)$ at $40{ }^{\circ} \mathrm{C}$ for 1 hour. The sample was stored in the dark at room temperature for 12 hours before injection in UHPLC. The hydrolyzed phenolic compounds were analyzed using an Agilent Poroshell 120 EC-C18 reversed phase column (2.7 $\mu \mathrm{m}$ particle size, $4.6 \times 150 \mathrm{~mm}$ ) on a Shimadzu Nexera UHPLC System (Shimadzu Nexera, Kioto, Japan) equipped with dual pump LC-30AD, on-line degasser DGU-20AS, column oven CTO-30A, auto sampler SIL-30AC, and diode array detector (SPD-M20A). Gradient separation was created from solvent A ( $2 \%$ acetic acid in water) and solvent $\mathrm{B}$ (acetonitrile) as follows: $0-1 \mathrm{~min}$, isocratic condition at $95 \% \mathrm{~A} ; 1-12 \mathrm{~min}$ linear gradient from 5 to $70 \% \mathrm{~B} ; 12-13 \mathrm{~min}$, linear gradient from 70 to $90 \% \mathrm{~B}$; isocratic condition kept up to $17 \mathrm{~min} ; 17$ min back to initial condition at $95 \% \mathrm{~A}$; isocratic step kept up to $22 \mathrm{~min}$ for column conditioning. The mobile phase flow rate was $450 \mu \mathrm{L} \mathrm{min}{ }^{-1}$. The column temperature was $30^{\circ} \mathrm{C}$. The injected volume for each sample was $5 \mu \mathrm{L}$. The detector was set at $280 \mathrm{~nm}$. Polyphenol quantification was obtained through calibration curves in the range of 10-600 ng of tyrosol and hydroxytyrosol injected on column with $\mathrm{R}^{2}$ values higher than 0.999 , in all cases. 


\subsection{Statistical Analysis}

All experiments were carried out in triplicate (with the exception of measurements on industrial samples reported in Tables 1 and 2). Data were expressed as means \pm standard deviation (SD). Differences of the analyzed compounds (tocopherols, polyphenols) among samples at different refining steps were calculated using one-way analysis of variance (ANOVA) with Tukey's post hoc procedure, with a level of significance at $p \leq 0.05$ (R Project for Statistical Computing; R Foundation for Statistical Computing, Wien, Austria). Principal component analysis was performed by using software R (R Core Team, 2013).

\section{Results and Discussions}

\subsection{Characterization of Selected Oil Samples}

The chemical characteristics of the analyzed samples are presented in Tables 1 and 2. Regarding quality parameters, free acidity of crude oils collected for the study ranged from 2.2 to $5.1 \%$ of free oleic acid/100 g oil. Samples 7, 8, and 9 are characterized by a free acidity close to the maximum level established by the IOC trade standard for edible virgin olive oil [1], which in this case also included ordinary virgin oil with the upper free acidity limit of 3.3\%. Meanwhile, with respect to EU Legislation, which set a limit for virgin olive oil of $2.0 \%$, all our samples were classified in the lampante category (Table 1). The specific extinction coefficient at 232, which provides information on the presence of primary oxidation products, classifies, according to the IOC trade standard, samples 2 and 6 as lampante and sample 5 as virgin, while the remaining samples meet the extra virgin olive oil (EVOO) limit. Regarding UV extinction coefficient at $270 \mathrm{~nm}$, samples 1, 3, and 6 lie within the limit fixed for ordinary virgin olive oil and samples 2 and 5 exceed this limit, thus being considered as lampante, while samples 7, 8, and 9 respect the limit value for EVOO. In all cases, levels of Delta-K, a parameter not considered for lampante oils in the EU regulations, were below the maximum level fixed for extra-virgin and virgin olive oils.

Table 1. Quality parameters of selected lampante oils.

\begin{tabular}{cccccccccc}
\hline \multirow{2}{*}{ Quality Parameters } & \multicolumn{10}{c}{ Samples } \\
\cline { 2 - 11 } & $\mathbf{1}$ & $\mathbf{2}$ & $\mathbf{3}$ & $\mathbf{4}$ & $\mathbf{5}$ & $\mathbf{6}$ & $\mathbf{7}$ & $\mathbf{8}$ & $\mathbf{9}$ \\
\hline Free acidity (\%) & 4.0 & 5.1 & 4.0 & 4.7 & 5.1 & 3.7 & 2.2 & 2.2 & 2.7 \\
K232 & 2.22 & 2.61 & 2.30 & 2.19 & 2.51 & 2.89 & 2.33 & 2.16 & 2.25 \\
K270 & 0.28 & 0.33 & 0.28 & 0.24 & 0.31 & 0.28 & 0.20 & 0.19 & 0.20 \\
Delta-K & 0.01 & 0.01 & 0.01 & 0.01 & 0.01 & 0.01 & 0.00 & 0.00 & 0.00 \\
\hline
\end{tabular}

On the other hand, the assessment of purity parameters reveals, as expected, that all samples had been obtained from olives by means of mechanical or other physical processes (Table 2).

The fatty acid (FA) composition (\%) of oil samples was studied within the official limits established for olive oil referred to in the IOC trade standard applied to olive oils and olive pomace oils. The results showed a typical olive oil FA profile with oleic acid higher than $66.2 \%$ and palmitic acid lower than $15.5 \%$ in all cases, among others. At the same time, according to the established limits, the absolute value of the difference between theoretical and experimental ECN42 content ( $\triangle E C N 42)$ was always lower than $|0.2|$.

Sterol composition (\%), which is one of the most suitable indicators for the determination of the botanical origin of oils, was also assessed revealing the absence of adulteration or contamination of olive oil with extraneous vegetable oils and/or refined ones. This scenario is also reinforced by the levels encountered of waxes $(\leq 300 \mathrm{mg} / \mathrm{kg})$ and erythrodiol + uvaol $(\leq 4.5 \%$ of total sterols). 
Table 2. Quality parameters of selected lampante oils.

\begin{tabular}{cccccccccc}
\hline Purity Parameters & \multicolumn{7}{c}{ Samples } \\
\cline { 2 - 9 } & $\mathbf{1}$ & $\mathbf{2}$ & $\mathbf{3}$ & $\mathbf{4}$ & $\mathbf{5}$ & $\mathbf{6}$ & $\mathbf{7}$ & $\mathbf{8}$ & $\mathbf{9}$ \\
\hline$\Delta$ ECN42 & $|0.1|$ & $|0.2|$ & $|0.1|$ & $|0.0|$ & $|0.1|$ & $|0.1|$ & $|0.1|$ & $|0.1|$ & $|0.1|$ \\
3,5-stigmastadienes (mg/kg) & 0.07 & 0.25 & 0.44 & 0.03 & 0.08 & 0.04 & 0.04 & 0.03 & 0.06 \\
Cholesterol (\%) & 0.20 & 0.28 & 0.16 & 0.17 & 0.22 & 0.20 & 0.16 & 0.14 & 0.16 \\
Brassicasterol (\%) & 0.07 & 0.08 & 0.11 & 0.06 & 0.08 & 0.06 & 0.00 & 0.01 & 0.02 \\
Campesterol (\%) & 3.28 & 3.45 & 3.41 & 3.42 & 3.39 & 3.29 & 3.37 & 3.55 & 3.52 \\
Stigmasterol (\%) & 1.45 & 1.58 & 1.80 & 1.94 & 1.87 & 1.55 & 1.61 & 1.48 & 1.51 \\
3-sitosterol (\%) & 94.2 & 93.6 & 93.4 & 93.6 & 93.5 & 93.6 & 93.4 & 93.9 & 93.8 \\
$\Delta 7$-avenasterol (\%) & 0.40 & 0.41 & 0.38 & 0.38 & 0.44 & 0.70 & 0.44 & 0.54 & 0.61 \\
$\Delta 7$-stigmastenol (\%) & 0.33 & 0.35 & 0.30 & 0.35 & 0.39 & 0.50 & 1.12 & 0.35 & 0.37 \\
Total sterols (mg/kg) & 1657 & 1483 & 1397 & 1432 & 1440 & 1623 & 1687 & 1649 & 1675 \\
Erythrodiol + uvaol (\%) & 2.96 & 2.50 & 2.41 & 2.68 & 1.97 & 2.32 & 2.43 & 2.24 & 3.04 \\
Waxes (mg/kg) & 246 & 252 & 261 & 295 & 248 & 246 & 170 & 152 & 207 \\
Aliphatic alcohols (mg/kg) & 305 & 234 & 255 & 256 & 211 & 322 & 340 & 318 & 380 \\
Fatty acid composition & & & & & & & & & \\
C16:0 (\%) & 11.9 & 12.6 & 11.7 & 12.1 & 12.4 & 14.0 & 15.3 & 15.8 & 15.4 \\
C18:0 (\%) & 3.0 & 2.6 & 3.0 & 2.9 & 2.8 & 2.5 & 2.3 & 2.3 & 2.3 \\
C18:1 ${ }^{\Delta 9 c}(\%)$ & 75.4 & 74.1 & 76.2 & 75.7 & 74.6 & 69.4 & 67.6 & 66.2 & 66.9 \\
C18:2 $\Delta 9 \mathrm{c}, 12 \mathrm{c}(\%)$ & 6.9 & 7.8 & 6.3 & 6.4 & 7.2 & 10.4 & 11.1 & 12.0 & 11.8 \\
C18:3 $\Delta 9 \mathrm{c}, 12 \mathrm{c}, 15 \mathrm{c}(\%)$ & 0.7 & 0.7 & 0.6 & 0.6 & 0.6 & 0.7 & 0.7 & 0.7 & 0.7 \\
\hline
\end{tabular}

Legend for fatty acids- $\mathrm{m}: \mathrm{n} \Delta \mathrm{x}, \mathrm{m}=$ number of carbon atoms, $n=$ number of double bonds, $\mathrm{x}=$ position of double bonds. $\triangle \mathrm{ECN} 42$ : difference between theoretical and experimental ECN42 content.

\subsection{Analysis of Polyphenols}

Phenolic compounds have been not only correlated with the oxidative stability of oils, but also with high health benefits. According to Regulation (EU) No 432/2012 ("Olive oil phenolic compounds contribute to the protection of blood lipids from oxidative stress"), health effects can be claimed only if the oil contains more than $5 \mathrm{mg}$ of hydroxytyrosol and its derivatives (e.g., oleuropein complex and tyrosol) in $20 \mathrm{~g}$ of oil [17]. The official HPLC method for the determination of biophenols in olive oils (Method COI/T.20/DOC. 28/Rev. 2-2017) is based on direct extraction of the biophenolic minor polar compounds from sample by a methanol/water $80 / 20(v / v)$ solution and subsequent quantification by HPLC-UV at $280 \mathrm{~nm}$ using syringic acid as internal standard [20]. However, this analytical approach allows us to obtain only a rough estimate of the amount of phenolic compounds because it is founded on the assumption that the UV response of all biophenols is similar, so the quantification is based on the ratio between the response factors of two of them. Therefore, although there are previous reports focused on the loss of phenolic compounds during refining of different vegetable oils, this is the first time that phenol content has been assessed by means of the UHPLC-UV technique after acid hydrolysis for obtaining phenolic acids in their free form. The sample treatment procedure, which employs sulfuric acid [21] for the hydrolysis of the phenolic extracts, allows for the proper quantification of hydroxytyrosol and tyrosol as well as the correct evaluation of their evolution during the different refining steps. Moreover, only a few studies have investigated the effect of refining on the olive oil matrix. For instance, Kostadinovic-Velickovska and Mitrev [22] observed a reduction of the total phenolic content from 19.23 to $1.82 \mathrm{mg}$ of gallic acid equivalent/10 $\mathrm{g}$ of oil in sunflower oil, while more recent research reported losses of $63 \%$ of polyphenolic compounds during neutralization, $16 \%$ during bleaching, and 67\% during the deodorization step of rapeseed oil [23].

Our experimental results show that oil samples collected for the study were characterized by initial low contents of total hydroxytyrosol and tyrosol, with values ranging from 43 to $68 \mathrm{mg} / \mathrm{kg}$, thus very far from the fixed level $(250 \mathrm{mg} / \mathrm{kg}$ ) for the health claim on "olive oil polyphenols" (Figure 1). Regarding the evolution of these compounds during refining, a complete removal of polyphenols occurred during the process as they were not detected starting from neutralized samples (Figure 1). Meanwhile, no 
significant changes were observed between crude and degummed oil samples. This finding is similar to those from a previous study [24]. In fact, $o$-diphenols can be easily oxidized under alkaline conditions, thus explaining their loss during this step [25]. On the contrary, other authors have also reported residual amounts of total polyphenols $(0.025-3.2 \mathrm{mg} / \mathrm{kg})$ measured by Folin-Ciocalteau $[26,27]$ in refined olive oils as well as different behaviors between tyrosol and hydroxytyrosol. For instance, Garcia et al. [25], showed that while most $o$-diphenols, including hydroxytyrosol, were lost due to oxidation and polymerization processes occurring under alkaline conditions, tyrosol was accumulated in the soapstocks and was mainly removed after the deodorization phase. Such discrepancies may be however explained by the different conditions that can be chosen for lampante olive oil refining, as well as by the different analytical approaches used for the evaluation of phenolic content (i.e., colorimetric versus chromatographic methods, hydrolyzed versus unhydrolyzed samples, etc.).

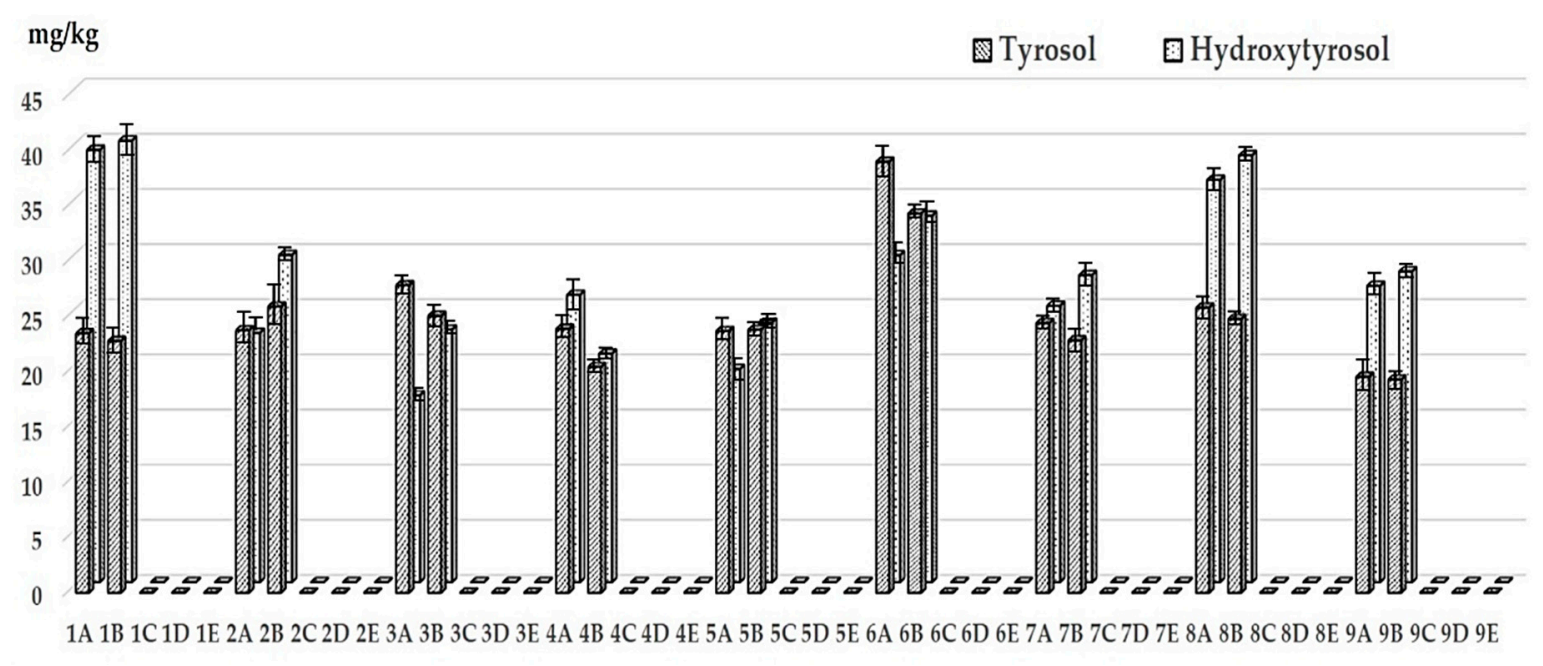

Figure 1. Effect of the refining steps on the hydroxytyrosol and tyrosol content ( $\mathrm{mg} / \mathrm{kg}$ oil). Legend for refining steps: A: Crude oil; B: degummed oil; C: neutralized oil; D: bleached oil; E: deodorized oil.

In general, however, our results confirm that polyphenols present in commercial olive oils come mostly from the virgin olive oil blended with refined oil.

\subsection{Analysis of Tocopherols}

For the analysis of tocopherols, a UHPLC method was developed and validated in-house. To improve tocopherol separation, a reversed-phase column packed with a $1.8-\mu \mathrm{m}$ particle size was employed (Agilent Eclipse PAH column, $4.6 \mathrm{~mm} \times 50 \mathrm{~mm}$ ) because of the faster separations that can be obtained compared to columns packed with 3- or 5- $\mu$ m particles [28]. UHPLC separation was performed under isocratic elution (methanol/acetonitrile $(60 / 40, v / v)$ ), thus eliminating the column re-equilibration step required in gradient separations. The total run time was 5 minutes, with a significant reduction in analysis time and solvent consumption compared to normal-phase IUPAC methodology for tocopherol analysis. Additionally, the reduction in solvent consumption $(3 \mathrm{~mL}$ per sample) also ensures compliance with the Registration, Evaluation, Authorisation and Restriction of Chemicals (REACH) directive (EC Reg. 1907/2006) [29], aimed at reducing, among other aspects, the environmental impact of the use of chemical reagents in laboratories.

For the evaluation of the linearity, a calibration curve for each $\alpha_{-}^{-}, \gamma_{-}^{-}$, and $\delta$-tocopherol was constructed. Different amounts of tocopherols were injected, ranging from 0.5 to $100 \mathrm{ng}$ on the column. A satisfactory linear dependence of the peak areas with analytes injected on the column was found, with a correlation coefficient higher of 0.999 in all cases. The wide linear dynamic range of the proposed methodology permits the analysis of wide-ranging contents of tocopherols in vegetable oils. Precision was determined by measuring the repeatability of peak areas on replicate injections $(n=9)$ with two 
different levels of tocopherol standards corresponding to 5 and 50 ng injected on the column. The experiment was also conducted by analyzing the tocopherol content in a commercial refined olive oil sample in order to highlight possible matrix effect. The latter is of extreme importance, especially considering that the proposed method minimizes sample preparation to a simple dilution of oil samples with isopropanol. Results were satisfactory, with repeatability relative standard deviation (RSDr) $\leq 2.5 \%$ in all cases, indicating excellent repeatability of the proposed analytical procedure for real oil sample analysis. The instrumental limits of quantification (LOQs) were $480 \mathrm{pg}$ ( $\alpha$-tocopherol), $230 \mathrm{pg}$ ( $\delta$-tocopherol), and $280 \mathrm{pg}$ ( $\gamma$-tocopherol) injected on the column, based on a signal to noise ratio $(\mathrm{S} / \mathrm{N})$ $=10: 1$.

Table 3 shows the level of total tocopherol content $(\mathrm{mg} / \mathrm{kg})$ in olive oil samples taken from the degumming, neutralizing, bleaching, and deodorizing steps.

Table 3. Effect of the refining steps on the total tocopherol content (mg/kg oil).

\begin{tabular}{cccccc}
\hline \multirow{2}{*}{ Samples } & \multicolumn{5}{c}{ Total Tocopherols } \\
\cline { 2 - 6 } & Crude oil & Degummed & Neutralized & Bleached & Deodorized \\
\hline $\mathbf{1}$ & $226 \pm 4^{\mathrm{bc}}$ & $225 \pm 2^{\mathrm{bc}}$ & $233 \pm 5^{\mathrm{c}}$ & $214 \pm 4^{\mathrm{a}}$ & $218 \pm 2^{\mathrm{ab}}$ \\
$\mathbf{2}$ & $170 \pm 8^{\mathrm{c}}$ & $152 \pm 7^{\mathrm{b}}$ & $138 \pm 4^{\mathrm{a}}$ & $142 \pm 3^{\mathrm{a}}$ & $157 \pm 2^{\mathrm{b}}$ \\
$\mathbf{3}$ & $154 \pm 3^{\mathrm{ab}}$ & $163 \pm 2^{\mathrm{bc}}$ & $169 \pm 5^{\mathrm{c}}$ & $149 \pm 3^{\mathrm{a}}$ & $167 \pm 2^{\mathrm{c}}$ \\
$\mathbf{4}$ & $188 \pm 1^{\mathrm{b}}$ & $171 \pm 5^{\mathrm{a}}$ & $188 \pm 4^{\mathrm{b}}$ & $216 \pm 3^{\mathrm{c}}$ & $181 \pm 4^{\mathrm{ab}}$ \\
$\mathbf{5}$ & $142 \pm 2^{\mathrm{b}}$ & $141 \pm 4^{\mathrm{b}}$ & $145 \pm 3^{\mathrm{b}}$ & $126 \pm 5^{\mathrm{a}}$ & $141 \pm 3^{\mathrm{b}}$ \\
$\mathbf{6}$ & $229 \pm 2^{\mathrm{a}}$ & $229 \pm 5^{\mathrm{a}}$ & $228 \pm 2^{\mathrm{a}}$ & $232 \pm 3^{\mathrm{a}}$ & $229 \pm 2^{\mathrm{a}}$ \\
$\mathbf{7}$ & $296 \pm 3^{\mathrm{b}}$ & $315 \pm 12^{\mathrm{bc}}$ & $310 \pm 3^{\mathrm{b}}$ & $328 \pm 6^{\mathrm{c}}$ & $271 \pm 5^{\mathrm{a}}$ \\
$\mathbf{8}$ & $324 \pm 6^{\mathrm{b}}$ & $338 \pm 5^{\mathrm{b}}$ & $333 \pm 2^{\mathrm{b}}$ & $330 \pm 5^{\mathrm{b}}$ & $288 \pm 18^{\mathrm{a}}$ \\
$\mathbf{9}$ & $344 \pm 5^{\mathrm{c}}$ & $346 \pm 3^{\mathrm{c}}$ & $335 \pm 12^{\mathrm{bc}}$ & $309 \pm 11^{\mathrm{ab}}$ & $287 \pm 13^{\mathrm{a}}$ \\
\hline
\end{tabular}

Results are expressed as the mean \pm standard deviation $(n=3)$. Total tocopherol content was calculated as the sum of $\alpha-, \gamma-$, and $\delta$-tocopherols. Values in the same row with different superscript letters are significantly different $(p \leq 0.05)$.

Data showed variations in the levels of tocopherols encountered in the nine crude oil samples, with values ranging from 142 to $344 \mathrm{mg} / \mathrm{kg}$. As expected, $\alpha$-tocopherol was the predominant form in all samples. An example of chromatogram obtained is reported in Figure 2.

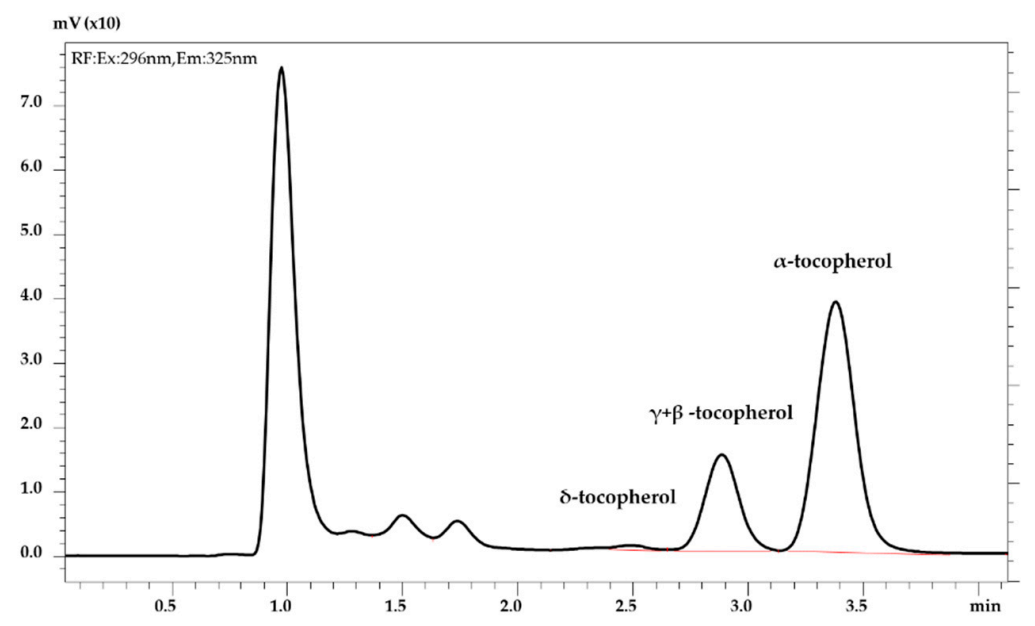

Figure 2. UHPLC-FL trace of tocopherols in lampante olive oil.

As already mentioned for phenolic compounds, for tocopherol only a few studies have evaluated the impact of the refining process on its content in olive oil samples, while most published articles are focused on other types of vegetable oils [30-32]. In general, a continuous decrease of tocopherol content has been observed during the refining procedure in sunflower, rapeseed, and soybean oils $[6,33]$. 
For instance, a huge decrease in total tocopherol content was observed in soybean oil (45.5\%), with a considerable reduction in individual and total tocopherol levels at almost every stage of refining. A gradual but not statistically significant decrease of tocopherol content $(14.0 \%)$ during the overall chemical refining process has been also reported for sunflower oil [12]. On the other hand, Suliman et al. [34] reported a significant decline of tocopherols, from $750 \mathrm{mg} / \mathrm{kg}$ in crude sunflower oil to 520 $\mathrm{mg} / \mathrm{kg}$ in refined samples. Major decreases have been observed during caustic neutralization because of the reduced stability of tocopherols in the presence of longer contact time with air and alkali [13]. Other researchers revealed a reduction of tocopherol content in olive oil of $37.7 \%$ (from $172.5 \mathrm{mg} / \mathrm{kg}$ to $107.5 \mathrm{mg} / \mathrm{kg}$ ) and $23.7 \%$ (from $107.5 \mathrm{mg} / \mathrm{kg}$ to $82.0 \mathrm{mg} / \mathrm{kg}$ ) after the degumming-bleaching and steam distillation steps, respectively, with a total loss of $52.5 \%$. In our research, however, the trends were not always clear-cut, and differences among samples behavior were found for different refining steps. Regarding the overall changes observed in tocopherol levels, the maximum decrease of about $16 \%$ was revealed for sample 9 . Similar reductions were also detected for samples 8,7 , and 2 , with final losses of about $11 \%, 8 \%$, and $7 \%$, respectively. It should be noted, however, that only four out of nine samples showed a statistically significant decrease $(p \leq 0.05)$, while in some samples $(1,4,5$, and 6$)$ the refining procedure did not induce any substantial decrease of total tocopherols. Moreover, in sample 3 , a significant increase $(8.4 \%)$ of tocopherols was encountered in the final deodorized sample. Some loss of tocopherols can also occur by evaporation during high temperature deodorization and physical refining, with the magnitude of this decrease depending on the conditions employed. For instance, in soybean oil, after $120 \mathrm{~min}$ at $300^{\circ} \mathrm{C}$ (a drastic treatment), the tocopherols almost completely disappeared, whereas the reduction during physical refining at $240{ }^{\circ} \mathrm{C}$ for $120 \mathrm{~min}$ was only about $15 \%-20 \%$ [35]. The latter conditions are closer to those ones employed for the industrial refining of our lampante oil samples where deodorization at $200{ }^{\circ} \mathrm{C}$ and $2 \mathrm{mbar}$ for about 2.5 hours was conducted, thereby explaining the reduced effect on total tocopherol contents.

In some cases, this trend could be interpreted as a concentration effect: higher initial free acidity in crude oil results in a greater loss of oil mass which does not necessarily involve the tocol fraction (Table 4). This aspect should be taken into consideration when examining the dynamics that influence the concentration of tocopherols of individual samples during the refining process. Therefore, besides the fact that tocopherols can suffer in the presence of oxygen and the alkaline medium, the small increases in tocols observed in our study for same samples during the degumming/neutralization phase may be associated with an increase in the tocopherol concentrations rather than their absolute values. In fact, as can be seen in Table 4, the loss rate of oil observed during the refining procedure is strongly related to the initial free acidity levels. As a result, a relationship between the initial free acidity of crude oil samples and the extent of decrease of tocopherols during refining could be hypothesized, as crude oil samples characterized by high free acidity resulted, with the exception of sample 2, in refined samples with smaller changes in final tocopherol content.

Table 4. Oil loss in the refining process.

\begin{tabular}{|c|c|c|c|c|c|c|c|c|c|}
\hline \multirow{2}{*}{ Quality Parameters } & \multicolumn{9}{|c|}{ Samples } \\
\hline & 1 & 2 & 3 & 4 & 5 & 6 & 7 & 8 & 9 \\
\hline Free acidity (\%) & 4.00 & 5.02 & 4.00 & 4.70 & 5.10 & 3.73 & 2.22 & 2.21 & 2.68 \\
\hline $\begin{array}{c}\text { Oil loss/chemical refining (\%)—neutralization } \\
\text { up to } 0.2 \% \text { of FFAs }\end{array}$ & 3.80 & 4.82 & 3.80 & 4.50 & 4.90 & 3.53 & 2.01 & 2.02 & 2.48 \\
\hline $\begin{array}{c}\text { Oil loss/physical refining (\%)-physical flash } \\
\text { neutralization up to } 0.02 \% \text { of FFAs }\end{array}$ & 3.78 & 4.80 & 3.78 & 4.48 & 4.88 & 3.51 & 2.00 & 1.99 & 2.46 \\
\hline
\end{tabular}

A general overview of our results can be highlighted by the PCA model reported in Figure 3. The plots show a quite clear homogeneity among samples as it is not possible to distinguish them based on the differences in tocopherol and polyphenol levels detected at different refining steps. The PCA showed only a small grouping effect for bleached and deodorized oil samples. This is probably due to 
the greater influences of phenolic acids changes occurring after the neutralization process, where they are completely removed from samples.
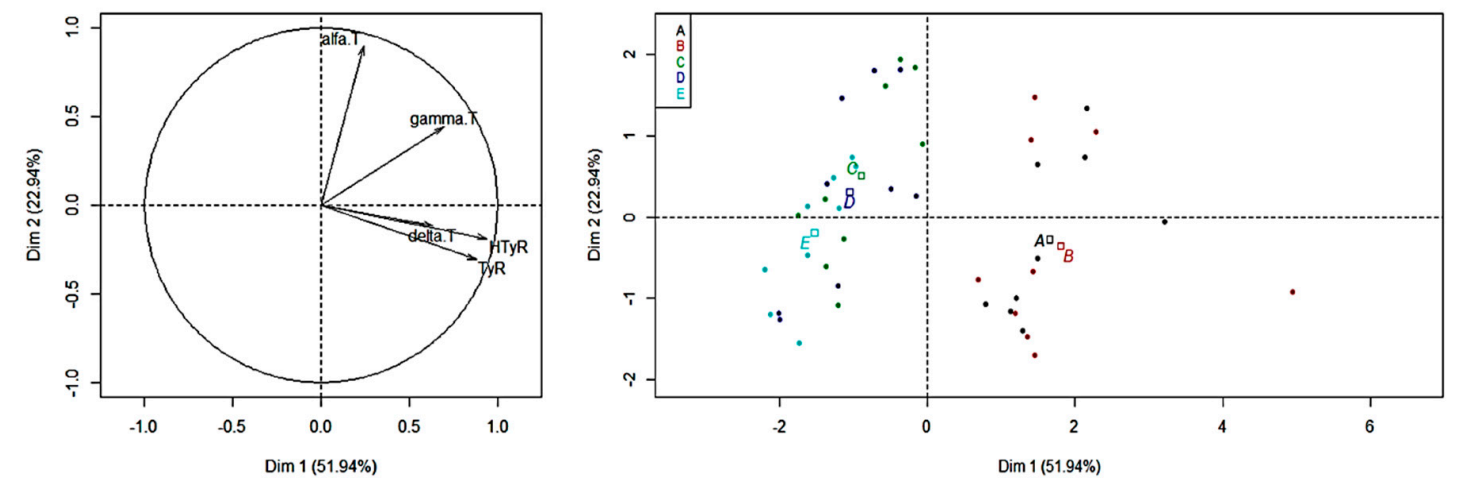

Figure 3. Principal component analysis (PCA) of phenolic compounds and tocols in oil samples across the refining procedure. (a) Loading plot of the variables; (b) Score plot of the samples. Legend. A: Crude oil; B: degummed oil; C: neutralized oil; D: bleached oil; E: deodorized oil; alfa T: $\alpha$-tocopherol; gamma T: $\gamma$-tocopherol; delta T: $\delta$-tocopherol; HTyR: hydroxytyrosol; TyR: tyrosol.

In conclusion, our study shows that the refining process has a marked effect on the final content of phenolic compounds, which are totally eliminated at the early stages of the refining procedure, while the effect on the level of tocopherols is minimal and in many cases insignificant $(p>0.05)$. These results also suggest that it is not always necessary to add tocopherols to refined samples with the aim of restoring natural tocols lost in the refining process, as the threshold value fixed by the international standards would be exceeded. In fact, it should be noted that the final concentration of tocopherols is higher than $200 \mathrm{mg} / \mathrm{kg}$ in five of nine samples (Table 3). Without any tocols additions, these values do not respect the maximum level imposed by the standards, leading to possible problems in international trade. On the other hand, crude oils characterized by initial tocopherol values lower than $200 \mathrm{mg} / \mathrm{kg}$, showed only a slight decrease in tocopherols in the finished products. These results are also consistent with those shown in Table 5, which reports data obtained by analyzing 11 commercial refined olive oil samples purchased at a local market. As can be seen, 8 out of 11 samples presented a total tocopherol content higher than the maximum allowed value, with 5 samples showing levels even greater than $300 \mathrm{mg} / \mathrm{kg}$.

Table 5. Total tocopherol content ( $\mathrm{mg} / \mathrm{kg}$ oil) of commercial olive oil samples.

\begin{tabular}{cc}
\hline & Total Tocopherols \\
\hline Samples & \\
$\mathbf{1}$ & $252 \pm 7$ \\
$\mathbf{2}$ & $481 \pm 5$ \\
$\mathbf{3}$ & $388 \pm 5$ \\
$\mathbf{4}$ & $272 \pm 9$ \\
$\mathbf{5}$ & $353 \pm 11$ \\
$\mathbf{6}$ & $174 \pm 3$ \\
$\mathbf{7}$ & $394 \pm 4$ \\
$\mathbf{8}$ & $207 \pm 8$ \\
$\mathbf{9}$ & $301 \pm 13$ \\
$\mathbf{1 0}$ & $108 \pm 9$ \\
$\mathbf{1 1}$ & $199 \pm 5$ \\
\hline
\end{tabular}

Total tocopherol content was calculated as the sum of $\alpha-, \gamma-$, and $\delta$-tocopherols.

Finally, this study supports the need for a revision of the IOC standard relative to the limit established for the addition of tocopherols to refined oils and therefore the maximum content allowed 
for commercial olive oils (mix of refined and virgin olive oils). This is extremely important, especially in the case of "high quality" olive oils which are obtained by mixing refined and extra virgin olive oil. In fact, due to a possible reduced loss of precious antioxidants in the refining phase, legal and economic trade issues could easily arise.

Author Contributions: Conceptualization, P.L. and L.C.; methodology, P.L., L.C. and S.M.; validation, P.L.; formal analysis, V.B. and P.L.; investigation, P.L., L.C. and V.B.; resources, L.C.; data curation, P.L., L.C. and D.P.; writing-original draft preparation, P.L. and L.C.; writing—review and editing, P.L., L.C. and D.P.; supervision, P.L., L.C. and S.M.; project administration, P.L. and L.C. All authors have read and agreed to the published version of the manuscript.

Funding: This research received no external funding.

Acknowledgments: The authors are grateful to Casa Oilio Spèrlonga SpA, Latina (IT) and Fratelli Carli S.p.A., Imperia (IT). for their donation of oil samples.

Conflicts of Interest: The authors declare no conflict of interest.

\section{References and Notes}

1. International Olive Oil Council. Trade Standard Applying to Olive Oil and Olive Pomace Oils; COI/T.15/NC No3/Rev.; International Olive Oil Council: Madrid, Spain, 2019.

2. Blatchly, R.; Delen, Z.; O'Hara, P. Processing: The most important hour. In The Chemical Story of Olive Oil: From Grove to Table, 1st ed.; Blatchly, R., Delen, Z., O’Hara, P., Eds.; Royal Society of Chemistry: London, UK, 2017; pp. 109-153.

3. Čmolík, J.; Pokorný, J. Physical refining of edible oils. Eur. J. Lipid Sci. Technol. 2000, 102, 472-486. [CrossRef]

4. Ruiz-Mendez, M.V.; de la Rosa, I.P.; Jimenez-Marquez, A.; Uceda-Ojeda, M. Elimination of pesticides in olive oil by refining using bleaching and deodorization. Food Addit. Contam. 2005, 22, 23-30. [CrossRef] [PubMed]

5. Boscou, D.; Blekas, G.; Tsimidou, M. Olive oil composition. In Olive Oil: Chemistry and Technology, 2nd ed.; Editor Boskou, D., Ed.; AOCS: Urbana, IL, USA, 2006; pp. 41-72.

6. Alpaslan, M.; Tepe, S.; Simsek, O. Effect of refining processes on the total and individual tocopherol content in sunflower oil. Int. J. Food Sci. Technol. 2001, 36, 737-739. [CrossRef]

7. Di Meo, F.; Lemaur, V.; Cornil, J.; Lazzaroni, R.; Duroux, J.L.; Olivier, Y.; Trouillas, P. Free radical scavenging by natural polyphenols: Atom versus electron transfer. J. Phys. Chem. A 2013, 10, 2082-2092. [CrossRef]

8. Deiana, M.; Rosa, A.; Cao, C.F.; Pirisi, F.M.; Bandino, G.; Dessi, M.A. Novel approach to study oxidative stability of extra virgin oils: Importance of $\alpha$-tocopherol concentration. J. Agric. Food Chem. 2002, 50, 4342-4346. [CrossRef] [PubMed]

9. Conte, L.; Bendini, A.; Valli, E.; Lucci, P.; Moret, S.; Maquet, A.; Lacoste, F.; Brereton, P.; García-González, D.L.; Moreda, W.; et al. Olive oil quality and authenticity: A review of current EU legislation, standards, relevant methods of analyses, their drawbacks and recommendations for the future. Trends Food Sci Tech. 2019, in press. [CrossRef]

10. Pérez, A.G.; León, L.; Pascual, M.; de la Rosa, R.; Belaj, A.; Sanz, C. Analysis of Olive (Olea Europaea L.) Genetic Resources in Relation to the Content of Vitamin E in Virgin Olive Oil. Antioxidants 2019, 8, 242. [CrossRef]

11. Špika, M.J.; Kraljić, K.; Koprivnjak, O.; Škevin, D.; Žanetić, M.; Katalinić, M. Effect of Agronomical Factors and Storage Conditions on the Tocopherol Content of Oblica and Leccino Virgin Olive Oils. J. Am. Oil Chem. Soc. 2015, 92, 293-1301.

12. Ergönül, P.G.; Köseoğlu, O. Changes in $\alpha-, \beta-, \gamma$ - and $\delta$-tocopherol contents ofmostly consumed vegetable oils during refining process. CyTA J. Food 2014, 12, 199-202. [CrossRef]

13. Tasan, M.; Demicri, M. Total and individual tocopherol contents of sunflower oil at different steps of refining. J. Eur. Food Res. Technol. 2005, 220, 251-254. [CrossRef]

14. Li, X.; Wang, S.C. Shelf Life of Extra Virgin Olive Oil and Its Prediction Models. J. Food Qual. 2018, 2018, 1-15. [CrossRef]

15. Choe, E.; Min, D.B. Mechanism and factors for edible oil oxidation. Compr. Rev. Food Sci. Food Saf. 2006, 5, 169-186. [CrossRef]

16. Codex Alimentarius, Standard for Olive Oils and Olive Pomace Oils Codex Stan 33-1981; Adopted in 1981. Revision: 1989, 2003, 2015. Amendment: 2009, 2013. 
17. EFSA Panel on Dietetic Products Nutrition and Allergens Scientific Opinion on the substantiation of health claims related to polyphenols in olive and protection of LDL particles from oxidative damage (ID 1333, 1638 1639, 1696 2865), maintenance of normal blood HDL cholesterol concentrations (ID 1639), maintenance of normal blood pressure (ID 3781), “anti-inflammatory properties” (ID 1882), “contributes to the upper respiratory tract health" (ID 3468), "can help to maintain a normal function of gastrointestinal tract" (3779), and "contributes to body defences against external agents" (ID 3467) pursuant to Article 13(1) of Regulation (EC) No. 1924/2006. EFSA J. 2011, 9, 2033-2058.

18. European Commission Regulation (EEC). No. 2568/91, on the characteristics of olive oil and olive-residue oil and on the relevant methods of analysis. Off. J. Eur. Union 1991, 248, 1-83.

19. International Olive Council. Determination of the Difference between Actual and Theoretical Content of Triacylglycerols with ECN 42 COI/T.20/Doc; No. 20 Rev. 3; International Olive Council: Madrid, Spain, 2001.

20. International Olive Council. Determination of Biophenols in Olive Oil by HPLC COI/T.20/Doc No. 29; International Olive Council: Madrid, Spain, 2009.

21. UNI/CT 003/GL 18 “Oli, grassi animali e vegetali e loro sottoprodotti, semi e frutti oleaginosi”. Progetto UNI1603053 Determinazione del Contenuto di Idrossitirosolo e Tirosolo Negli Oli di Olive-Metodo HPLC; 2017.

22. Sanja, K.-V.; Sasa, M. Characterization of fatty acid profile, polyphenolic content and antioxidant activity of cold pressed and refined edible oils from Macedonia. J. Food Chem. Nutr. 2013, 1, 16-21.

23. Kraljić, K.; Škevin, D.; Barišić, L.; Kovačević, M.; Obranović, M.; Jurčević, I. Changes in 4-vinylsyringol and other phenolics during rapeseed oil refining. Food Chem. 2015, 187, 236-242. [CrossRef]

24. Cortesi, N.; Ponziani, A.; Fedeli, E. Caratterizzazione degli oli virgini e raffinati mediante HPLC dei componenti polari. Nota peliminari. Riv. Ital. Sostanze Grasse 1981, 58, 108-114.

25. García, A.; Ruiz-Méndez, M.V.; Romero, C.; Brenes, M. Effect of refining on the phenolic composition of crude olive oils. J. Am. Oil Chem. Soc. 2006, 83, 159-164. [CrossRef]

26. Artajo, L.S.; Romero, M.P.; Morelló, J.R.; Motilva, M.J. Enrichment of refined olive oil with phenolic compounds: Evaluation of their antioxidant activity and their effect on the bitter index. J. Agric. Food Chem. 2006, 54, 6079-6088. [CrossRef]

27. Venturi, F.; Sanmartin, C.; Taglieri, I.; Nari, A.; Andrich, G.; Terzuoli, E.; Donnini, S.; Nicolella, C.; Zinnai, A. Development of phenol-enriched olive oil with phenolic compounds extracted from wastewater produced by physical refining. Nutrients 2017, 9, 916. [CrossRef]

28. Núñez, O.; Gallart-Ayala, H.; Martins, C.P.; Lucci, P. New trends in fast liquid chromatography for food and environmental analysis. J. Chromatogr. A 2012, 1228, 298-323. [CrossRef] [PubMed]

29. European Parliament and Council. Regulation (EC) no. 1907/2006 of 18 December 2006 concerning the Registration, Evaluation, Authorisation and Restriction of Chemicals (REACH), establishing a European Chemicals Agency, amending Directive 1999/45/EC and repealing Council Regulation (EEC) no. 793/93 and Commission Regulation (EC) no. 1488/94 as well as Council Directive 76/769/EEC and Commission Directives 91/155/EEC, 93/67/EEC, 93/105/EC and 2000/21/EC. Off. J. Eur. Union 2006, 396, 30.

30. Pal, U.S.; Patra, R.K.; Sahoo, N.R.; Bakhara, C.K.; Panda, M.K. Effect of refining on quality and composition of sunflower oil. J. Food Sci. Technol. 2015, 52, 4613-4618. [CrossRef] [PubMed]

31. Van Hoed, V.; Depaemelaere, G.; Ayala, J.; Santiwattana, P.; Verhe, R.; De Greyt, W. Influence of chemical refining on the major and minor components of rice brain oil. J. Am. Oil Chem. Soc. 2006, 83, 315-321. [CrossRef]

32. Szydlowska-Czerniak, A.; Trokowski, K.; Karlovits, G.; Szlyk, E. Effect of refining processes on antioxidant capacity, total contents of phenolics and carotenoids in palm oils. Food Chem. 2011, 129, 1187-1192. [CrossRef]

33. Wu, Y.; Zhou, R.; Wang, Z.; Wang, B.; Yang, Y.; Ju, X.; He, R. The effect of refining process on the physicochemical properties and micronutrients of rapeseed oils. PLoS ONE 2019, 14, 1-16. [CrossRef]

34. Suliman, T.M.A.; Jiang, J.; Liu, Y. Chemical refining of sunflower oil: Effect on oil stability, total tocopherol, free fatty acids and colour. Int. J. Eng. Sci. Technol. 2013, 5, 449-454.

35. Carrillo, W. Food production and technology. In Biotechnology and Food Production, 1st ed.; Carrillo, W., Ed.; ED-Tech Press: London, UK, 2019; pp. 219-246.

(C) 2020 by the authors. Licensee MDPI, Basel, Switzerland. This article is an open access article distributed under the terms and conditions of the Creative Commons Attribution (CC BY) license (http://creativecommons.org/licenses/by/4.0/). 